\title{
The Molecular Epidemiology of a Heterosexual Subtype B HIV Epidemic: the Latest Results from the Caribbean
} JK Carr* ${ }^{*}$, Y Nadai ${ }^{1}$, L Eyzaguirre ${ }^{1}$, M Charurat ${ }^{2}$, A Sill ${ }^{2}$, N Jack ${ }^{3}$, P Figueroa ${ }^{4}$, JW Pape ${ }^{5}$, E Guerrero ${ }^{6}$, F Cleghorn ${ }^{7}$ and W Blattner ${ }^{2}$

Address: ${ }^{1}$ U.S. MHRP, Rockville, MD, ${ }^{2} \mathrm{IHV}$, University of Maryland, Baltimore, MD, ${ }^{3}$ MRFTT, Port of Spain, Trinidad, ${ }^{4}$ Ministry of Health, Kingston, Jamaica, ${ }^{5}$ GHESKIO, Port au Prince, Haiti, ${ }^{6}$ COPRESIDA, Santo Domingo, Dominican Republic, Washington, DC and ${ }^{7}$ Futures Group, Washington, DC

Email: JK Carr* - carrj@umbi.umd.edu

* Corresponding author ‡Presenting author

from 2005 International Meeting of The Institute of Human Virology

Baltimore, USA, 29 August - 2 September 2005

Published: 8 December 2005

Retrovirology 2005, 2(SuppI I):S77 doi:I0.1186/1742-4690-2-SI-S77

\section{Introduction}

The HIV epidemic in the Caribbean is one of the few epidemics in the world that is dominated by subtype $B$ and has a heterosexual transmission pattern. Close examination of the Caribbean subtype B viruses by full genome sequencing may shed light on the epidemic. Methods: Serum samples from Trinidad and Tobago (TT), Jamaica (JM), Haiti (HT) and the Dominican Republic (DO) were collected for characterization. CDNA synthesized from viral RNA was PCR amplified and sequenced with an ABI 3100 sequencer.

\section{Results}

Over 60 strains were analyzed and all but one was subtype B. Phylogenetically there were no island-specific or Caribbean-specific genetic clusters, though a majority of new TT samples retained the signature threonine deletion in the V3 loop. One sample from DR was a unique BC recombinant having gag and $e n v$ from subtype $\mathrm{C}$ and pol from subtype B. Glycosylation patterns in the Caribbean gp160's were different from those of other subtype B strains from the epidemic.

\section{Conclusion}

The genetic isolation of the TT strains from the mid1990 's is no longer visible in the most recent samples, though the majority still retains the earlier signature in V3. Glycosylation differences between the Caribbean envs and those in North America may relate to natural selection of the Caribbean virus for heterosexual transmission. 